\title{
Are Cell-Phone and Other Digital Devices Safe To Human Health?
}

Md. Nurul Amin ${ }^{1}$

Last two decades have experienced tremendous growth in communication technology. With the advent of digital technology, we can now communicate to any parts of the world by just touching the screen of the cell-phone. Keeping pace with the communication technology, the world's economy is growing faster. However, these digital devices are not without side-effects. International Agency for Research on Cancer (IARC) published cancer risks from Radiofrequency (RF) radiation. Human epidemiological studies gave evidence of increased risk for glioma and acoustic neuroma with exposure to RF radiation. $\mathrm{RF}$ radiation was classified as Group 2B, a possible human carcinogen. Further epidemiological, animal and mechanistic studies have strengthened the association. Besides, the carcinogenic effect of non-ionizing radiation emitted from cordless digital devices, numerous health effects have already been claimed to occur. Animal model studies showed that long-term exposure of $2.4 \mathrm{GHz}$ RF emitted from Wi-Fi (2420 $\mu \mathrm{W} / \mathrm{kg}, 1 \mathrm{~g}$ average) affects some of the reproductive parameters of male rats (head defects of sperms and weight of the epididymis) suggesting that Wi-Fi users should avoid long-term exposure of RF emissions from Wi-Fi equipment. ${ }^{1}$

Individuals sensitive to electromagnetic fields often experience cognitive impairments which they believe are due to exposure to RF. Furthermore, they complaint of headache and perceive that such symptom is caused by the RF EMF exposure. ${ }^{2}$ Headache is an important warning sign that body temperature is rising to a risky level suggesting that when RF heats body tissues, body temperature and other vital physiological parameters such as heart rate and blood pressure may change. ${ }^{3}$ In spite of this, most countries have taken little or no measure to reduce exposure and educate people on health hazards from RF radiation. On the contrary ambient levels have increased ${ }^{4}$ causing concern about its impact on human health. With the increasing use of third generation (3G) mobile phones, social concerns have arisen concerning the possible health effects of radio frequencyelectromagnetic fields (RF-EMFs) emitted by mobile phones in humans. ${ }^{5}$ With new technology, increasing environmental exposure levels are found as in measurements of ambient RF radiation at Stockholm Central Station and Stockholm Old Town in Sweden. 4,6

The exposure guideline used by many agencies was established in 1998 by the International Commission on Non-Ionizing Radiation Protection (ICNIRP) and was based only on established short-term thermal (heating) effects from RF radiation neglecting non-thermal biological effects. The heating effects arise when radiation is so high that it warms up the whole body by $1^{\circ} \mathrm{C}$ or more after $30 \mathrm{~min}$ exposure at $4 \mathrm{~W} / \mathrm{kg}$ specific absorption rate. ${ }^{7}$

Association between radiofrequency emissions and cancer risk has become a much talked-about issue among the medical community these days. Epidemiological studies provided supportive evidence of increased risk for head and brain tumours, i.e., acoustic neuroma and glioma. RF radiation from devices that emit non-ionizing $\mathrm{RF}$ radiation in the frequency range $30 \mathrm{kHz}-300 \mathrm{GHz}$, is a Group 2B, i.e. a 'possible', human carcinogen. ${ }^{8,9}$ Later studies have corroborated these findings and have thus strengthened the evidence. ${ }^{10-13}$ For

\footnotetext{
Author information:

${ }^{1}$ Dr. Md. Nurul Amin, Associate Professor (Part-time) \& Executive Editor, Ibrahim Cardiac Medical Journal, Ibrahim Cardiac Hospital \& Research Institute, Shahbag, Dhaka.
}

Correspondence : Dr. Md. Nurul Amin, Mobile:01753178452, e-mail:mdamin01@yahoo.com 
children this risk may be accentuated because of a cumulative effect during a long lifetime use. ${ }^{14}$ Developing and immature cells can also be more sensitive to exposure to RF radiation. ${ }^{15}$ An animal model study report was released from NTP under the NIH in USA (the largest ever animal study on cell phone RF radiation and cancer). ${ }^{16} \mathrm{An}$ increased incidence of glioma in the brain and malignant schwannoma in the heart was found in rats. Acoustic neuroma or vestibular schwannoma is a similar type of tumour as the one found in the heart, although benign. This animal study supported human epidemiological findings on RF radiation and brain tumour risk. ${ }^{13}$

Another concern whether radiofrequency emission tells on fertility is also a debatable issue. An animal model study was carried out to investigate longterm effects of radiofrequency radiation (RFR) emitted from a Wireless Fidelity (Wi-Fi) system on testes. ${ }^{1}$ The study was carried out on 16 Wistar Albino adult male rats by dividing them into two groups such as control $(n=8)$ and exposure $(n=$ 8 ). Rats in the exposure group were exposed to 2.4 GHz RF radiation for $24 \mathrm{~h} / \mathrm{d}$ during 12 months (1 year). The same procedure was applied to the rats in the control group except the Wi-Fi system was turned off. The study demonstrated increased abnormal morphology (head defects) of the sperms in the exposure group compared to the control group $(p<0.05)$, while weight of the epididymis and seminal vesicles, seminiferous tubules diameter and tunica albuginea thickness were decreased in the exposure group $(p<0.01, p$ $<0.001, p<0.0001)$. Although the study suffers from small sample size, the significant difference in outcome between the study and control group indicates that long-term exposure to Wi-Fi may not be safe to reproductive health.

The possible effect of radiofrequency emissions on behavioral symptoms has created immense dispute in the last few decades. The number of people with self-reported electromagnetic hypersensitivity (EHS), who complain of various subjective symptoms such as headache, dizziness and fatigue, has also increased during the last couple of decades. However, the origins of EHS remain unclear. Cross-sectional survey studies in different countries have reported that EHS subjects experience non-specific subjective symptoms (e.g., headache, dizziness, fatigue, sleep disorder) associated with EMF exposure: $1.5 \%$ in Sweden, ${ }^{17} 3.2 \%$ in California ${ }^{18}$ and $5 \%$ in Switzerland. ${ }^{19}$ For some individuals, the symptoms can have lifestyle-changing consequences. ${ }^{20}$

Exposure to radio-frequency and cognitive effect is also no less disputed issue. Malek and associates ${ }^{21}$ in an experimental study on 200 subjects, however, demonstrated that there is no significant effect of short-term GSM (Global System for Mobile Communication) and UMTS (Universal Mobile Telecommunications System) on body temperature (BT) and blood pressure indicating that body temperature and blood pressure are not affected by short term GSM and UMTS. But it is still believed that the existence of RF-EMF exposure effects from the mobile phones, Wi-fi and their base stations have not been rigorously tested to show their adverse consequences with scientific certainty.

The basis for limiting exposure according to ICNIRP is that 'Only established effects were used as the basis for the proposed exposure restrictions. Induction of cancer from long-term EMF exposure was not considered to be established, and so these guidelines are based on short-term, immediate health effects such as stimulation of peripheral nerves and muscles, shocks due to elevated tissue temperatures resulting from absorption of energy during exposure to EMF. In the case of potential longterm effects of exposure, such as an increased risk of cancer, ICNIRP concluded that available data are insufficient to provide a basis for setting exposure restrictions, although epidemiological research has provided suggestive evidence of an association between possible carcinogenic effects. ${ }^{22}$

A Fact Sheet from World Health Organization issued in June 2011 shortly after the IARC cancer classification in May 2011 stated that 'To date, no adverse health effects have been established as being caused by mobile phone use. ${ }^{7}$ In the WHO Fact Sheet it was also stated that 'WHO will 
conduct a formal risk assessment of all studied health outcomes from radiofrequency fields exposure by 2012 . Why WHO was so keen to make a new risk evaluation shortly after the IARC evaluation. The statement was not based on scientific evidence at that time on a carcinogenic effect from RF radiation. And it was hardly expected that new studies would be published in short time changing the classification of RF radiation as a possible, Group 2B, human carcinogen. Considering the WHO statement of 'no adverse health effects' the aim might have been to undermine the IARC decision and give the telecom industry a 'clean bill' of health. ${ }^{13}$ It might, however, be argued that as a result of the IARC classification, it was necessary for WHO to also look at other effects, and not just tumours.

Therefore, there is an urgent need to study the issue so as to shed some light on safety of mobile technology. It is also of utmost need to determine the level of radiofrequency emitted from mobile phones and whether the exposure level is too far that recommended by ICNIRP. Such studies will be of much help for making recommendation to the concerned legislative authority of the Govt. to constantly monitor the RF radiation exposure from the mobile phone, Wi-fi and other digital devices and their base-stations to keep people safe from their harmful effect.

\section{REFERENCES:}

1. Dasdag S, Taş M, Akdag MZ, Yegin K. Effect of longterm exposure of $2.4 \mathrm{GHz}$ radiofrequency radiation emitted from Wi-Fi equipment on testes functions. Electromagn Biol Med 2015;34(1):37-42.doi: 10.3109/ 15368378.2013.869752.

2. Röösli M, Moser M, Baldinini Y, Meier M, Braun-Fahrländer C. Symtpoms of ill health ascribed to electromagnetic field exposure-a questionnaire survey. International Journal of Hygiene Environmental Health 2004;207: 141-50.

3. McKinlay AF. Review of the scientific evidence for limiting exposure to electromagnetic fields $(0-300 \mathrm{GHz})$. Docs NRPB 2004;15;83.

4. Hardell L. World Health Organization, radiofrequency radiation and health - a hard nut to crack (Review). Int J Oncol 2017;51(2):405-413.doi:10.3892/ijo.2017.4046 PMCID:PMC5504984.
5. Heinrich S, Thomas S, Heumann C, vonKries R, Radon $\mathrm{K}$. Association between exposure to radiofrequency electromagnetic fields assessed by dosimetry and acute symptoms in children and adolescents: a population based cross-sectional study. Environ Health 2010;9:75. doi: 10.1186/1476-069X-9-75.

6. Hardell L, Koppel T, Carlberg M, Ahonen M, Hedendahl L. Radiofrequency radiation at Stockholm Central Railway Station in Sweden and some medical aspects on public exposure to RF fields. Int J Oncol 2016;49:1315-324.

7. Hardell L. World Health Organization, radiofrequency radiation and health - a hard nut to crack (Review). Int J Oncol 2017;51(2):405-13. doi: 10.3892/ijo.2017.4046

8. Baan R, Grosse Y, Lauby-Secretan B, El Ghissassi F, Bouvard V, Benbrahim-Tallaa L, Guha N, Islami F, Galichet L. Carcinogenicity of radiofrequency electromagnetic fields. Lancet Oncol 2011;12:624-26. doi: 10.1016/S1470-2045(11)70147-4.

9. IARC (International Agency for Research on Cancer). Non-Ionizing Radiation, Part 2: Radiofrequency Electromagnetic Fields. WHO Press; Lyon, France: 2013. IARC monographs on the evaluation of carcinogenic risks to humans, Volume 102 [cited 20-Jan-19]. Available from:http://monographs.iarc.fr/ENG/Monographs/vol102/mono102.pdf. Accessed April 1, 2017.

10. Hardell L, Carlberg M, Söderqvist F, Hansson Mild $\mathrm{K}$. Case-control study of the association between malignant brain tumours diagnosed between 2007 and 2009 and mobile and cordless phone use. Int J Oncol 2013;43:1833-845.

11. Hardell L, Carlberg M, Koppel T, Hedendahl L. High radio-frequency radiation at Stockholm Old Town: An exposimeter study including the Royal Castle, Supreme Court, three major squares and the Swedish Parliament. Mol Clin Oncol 2017;6:462-76.

12. Coureau G, Bouvier G, Lebailly $P$, Fabbro-Peray $P$, Gruber A, Leffondre K, Guillamo JS, Loiseau $H$, Mathoulin-Pélissier S, Salamon R, Baldi I. Mobile phone use and brain tumours in the CERENAT case-control study. Occup Environ Med 2014;71(7):514-22. doi: 10.1136/oemed-2013-101754.

13. Carlberg M, Hardell L. Evaluation of mobile phone and cordless phone use and glioma risk using the Bradford Hill viewpoints form 1965 on association or causation. Bio Med Res Int 2017;2017:9218486. doi: $10.1155 / 2017 / 9218486$.

14. Hedendahl L, Carlberg M, Hardell L. Electromagnetic hypersensitivity - an increasing challenge to the medical profession. Rev Environ Health 2015;30:209-15. doi: 10.1515/reveh-2015-0012.

15. Markovà E, Malmgren LO, Belyaev IY. Microwaves from mobile phones inhibit 53BP1 focus formation in human stem cells more strongly than in differentiated cells: Possible mechanistic link to cancer risk. Environ Health 
Perspect 2010;118:394-99.

16. Wyde $M$, Cesta $M$, Blystone $C$, Elmore $S$, Foster $P$, Hooth M, Kissling G, Malarkey D, Sills R, Stout M, et al. Report of Partial findings from the National Toxicology Program Carcinogenesis Studies of Cell Phone Radiofrequency Radiation in Hsd: Sprague Dawley ${ }^{\circledR}$ SD rats (Whole Body Exposures) US National Toxicology Program (NTP); 2016 [cited 1 April 2017]. Available at: http://biorxiv.org/content/biorxiv/early/2016/05/26/055699.full.pdf.doi: org/10.1101/055699.

17. Hillert L, Berglind N, Arnetz BB, Bellander T. Prevalence of self-reported hypersensitivity to electric or magnetic fields in a population-based questionnaire survey. Scand J Work Environ Health 2002;28:33-41. doi: 10.5271/sjweh.644.

18. Levallois P, Neutra R, Lee G, Hristova L. Study of self-reported hypersensitivity to electromagnetic fields in California. Environ Health Perspect 2002;110(Suppl 4):619-23.

19. Schröttner J, Leitgeb N, Hillert L. Investigation of electric current perception thresholds of different EHS groups. Bioelectromagnetics 2007;28:208-13. doi: 10.1002/bem.20294.

20. Mild KH, Repacholi M, Deventer E, Ravazzani P, editor. Proceedings of an International Workshop on EMF Hypersensitivity: 25-27 October 2004. World Health Organization; 2006.

21. Malek F, Rani KA, Rahim HA and Omar MH . Effect of Short-Term Mobile Phone Base Station Exposure on Cognitive Performance, Body Temperature, Heart Rate and Blood Pressure of Malaysians. Sci Rep 2015;5:13206. doi: $10.1038 /$ srep13206 PMCID: PMC4541152.

22. International Commission on Non-Ionizing Radiation Protection (ICNIRP), Guidelines For Limiting Exposure To Time-Varying Electric, Magnetic And Electromagnetic Fields (Up To $300 \mathrm{Ghz}$ ) Published In: Health Physics 74(4):494-522;1998 [cited 20 January 2019]. Available from: https://www.icnirp.org/cms/upload/publications/ICNIRPemfgdl.pdf 